\title{
Prevalence of intestinal protozoan parasites in stray and domicile dogs in Ilorin, North Central, Nigeria
}

\author{
Ayodele ADEDOJA ${ }^{1 *}$, John Adebola OSHODI ${ }^{2}$, Ajibola Aliu AKANBI ${ }^{3}$ and \\ Shola Babatunde ${ }^{4}$ \\ ${ }^{1}$ Department of Medical Microbiology \& Parasitology, University of Ilorin, Ilorin. Nigeria. \\ ${ }^{2}$ Department of Medical Microbiology \& Parasitology, University of Ilorin Teaching Hospital, Ilorin. Nigeria. \\ ${ }^{3}$ Department of Medical Microbiology \& Parasitology, University of Ilorin, Ilorin. Nigeria. \\ ${ }^{4}$ Department of Microbiology, Kwara State University, Ilorin. Nigeria. \\ *Corresponding author; E-mail: ayodeleadedoja@gmail.com; Tel.:+2347037986672
}

\begin{abstract}
Uncontrolled population of stray and domicile dogs with intestinal protozoan in close proximity to increasing densities of human population in urban environments is a common fact in developing countries, in conjunction with the lack of veterinary attention and zoonotic awareness, increases the risks of disease transmission. We examined using standard method 108 stool specimens of stray and domicile dogs collected randomly from Ilorin, state capital of Kwara State, Nigeria for intestinal protozoan. The prevalence of intestinal parasites from both stray and domicile dogs was 64(59.3\%). Three parasites were encountered; Anchylostoma sp, Cryptosporidium sp and Isospora sp. Female dogs were more infected (48.9\%) than male dogs (11.1\%) $(\mathrm{P}<0.001)$ while the stray dogs had more intestinal parasitic infection $(68.3 \%)$ than domicile dogs $(46.7)$. More of Cryptosporidium sp was observed among strayed dogs (36.5\%). Double infection was highest in stray dogs $(12.7 \%)$ than in domicile dogs $(4.4 \%)$ but not statistically significant $(\mathrm{p}=0.051)$. Consistent sanitary education must be included in public health government actions as a first step for the control of intestinal parasites in dogs and good sanitation and hygiene should be encouraged minimize environmental contamination and contact with the infectious oocysts that may be shed by dogs.

(C) 2014 International Formulae Group. All rights reserved.
\end{abstract}

Keywords: Stray dog, domicile dog, zoonoses, Crysptosporidium, Isospora.

\section{INTRODUCTION}

Uncontrolled population of stray and domesticated dogs in close proximity to increasing densities of human population in urban environments is a common fact in developing countries, which, in conjunction with the lack of veterinary attention and zoonotic awareness, increases the risks of disease transmission (Okoye et al., 2011). In most Nigerian cities, government actions such as providing the population with information about the risks of zoonotic disease transmitted by domestic animals, and control of stray animals are practically non-existent, resulting in an increasing risk of exposure to zoonoses transmitted by these animals. In developing countries, the risk of zoonotic infection related to domiciled dogs is high because the obligations placed on dog owners are less restrictive (Edet et al., 2014). As a 
consequence, even domiciled animals go on harboring parasitic infections, including those to which treatment and effective control methods are available. The presence of these animals in close contact with people constitutes a high potential risk, especially to children and immune-compromised individuals (Robertson et al., 2000). To our knowledge there had not been study on intestinal protozoan among the stray and domicile dogs in Ilorin city. Considering aspects related to public health study of the prevalence of parasite protozoan infection in dogs should therefore be continuous task, with the most relevant aim being the establishment of control measures (Oliveira-Sequeira et al., 2002). The aim of our investigation was to determine the prevalence of protozoan infections in stray and domicile dogs and examine the health risk to pet owners in Ilorin, North Central, Nigeria.

\section{MATERIALS AND METHODS}

\section{Source of samples}

Between November 2013 and May 2014, faecal samples were collected in plastic containers from 108 stray and domicile dogs of ages varying between 1 and 4 years. The age of the stray and domicile dogs were given by the owners. The dogs were of a variety of breeds from Ilorin the state capital of Kwara State, Nigeria. The study was conducted in the city of Ilorin (North Central Nigeria), and the neighboring rural communities (longitude $4^{\circ}$ $30^{\prime}-4^{\circ} 45^{\prime} \mathrm{N}$ and latitude $8^{\circ} 28^{\prime}-8^{\circ} 38^{\prime} \mathrm{E}$ ). Ilorin is an urban centre and the capital of Kwara State. The city covers an area of about 38 square miles, with an estimated population of 1.4 million people. It is located in Nigeria's central savannah region with intense rainfalls from April to October and daily temperatures between $23{ }^{\circ} \mathrm{C}$ and $37{ }^{\circ} \mathrm{C}$. Living conditions are particularly poor. Substantial proportion of the dog owners have no access to veterinary services. Therefore, most dogs have never been treated for any form of parasitic diseases prior to the study. In addition, most dogs are not vaccinated.

\section{Parasitological procedures}

Fresh faecal samples were processed for helminth eggs and protozoan cysts and/or oocysts using a standard method (Cheesbrough, 2009). Faecal specimens were concentrated by the formalin-ether sedimentation method. Faecal smears from the sediment $(20 \mu \mathrm{L})$ were made and stained by the modified Ziehl-Neelson technique. It was air-dried and fixed with methanol for 2-3 minutes. The smear was stained with unheated carbol fuchsin for 15 minutes. Smears were then washed off with water, decolorize with $1 \%$ acid alcohol for 10-15 seconds and wash off with water after which it was counter stained with $0.5 \%$ malachite green for 30 seconds. The smears were washed off with water and the slide allowed to stand in the in a draining rack for the smear to dry. They were examined microscopically for oocysts using a low power magnification to detect the oocysts and the oil immersion objective to identify them.

The complete surface of the smear was examined for protozoan oocysts (Causape et al., 1996).

\section{Statistical analysis}

All the analyses were made using chisquared tests for two independent proportions employing the SSPS version 16.0

\section{RESULTS AND DISCUSSION}

Prevalence of intestinal parasites stratified by age is shown in Table 1 and indicates that, of 108 stools examined for intestinal parasites from both stray and domicile dogs, 64(59.3\%) dogs were positive for intestinal parasites. Three parasites were encountered, one nematode and two protozoan. These were Anchylostoma sp, Cryptosporidium sp and Isospora sp. Dogs of age 1 year old were most infected $(77.8 \%)$ while dogs of age 2 years old were least infected $(56.2 \%)$. In the category of nematode, dogs of age one year old were more infected $(33.3 \%)$ while the least infection was observed in both age 2 and 4 years $(25.0 \%)$ 
respectfully. Among dogs infected with Cryptosporidium sp, more infection was seen in age 1 year old dogs $(44.4 \%)$ and least infection in age 3 years old dog (19.4\%). Dogs in age 4 years were more infected with Isospora sp (25.0\%) and least infection seen in age 2 years $(17.2 \%)$. Prevalence of intestinal parasites stratified by sex is shown in Table 2. Female dogs were more infected $(68.9 \%)$ than male dogs $(52.4 \%)(\mathrm{P}=0.085)$. However, male dogs had more infection of Anchylostoma sp (27.0\%) than female dogs (26.7\%) $(\mathrm{P}=0.085)$. Female dogs were more infected with Cryptosporidium sp (48.9\%) than males $(11.1 \%)(\mathrm{P}=0.000)$, while male dogs were more infected with Isospora $\mathrm{sp}$ $(20.6 \%)$ than female dogs $(13.3 \%)(\mathrm{P}=0.326)$. Prevalence of intestinal parasites in dogs by house type is shown in Table 3. The stray dogs had more intestinal parasitic infection (68.3\%) than domicile dogs $(46.7 \%)$. More of Anchylostoma sp was observed in stray dogs $(31.7 \%)$ and less observed in domicile dogs (20.0\%). Cryptosporidium sp was observed among strayed dogs was higher $(36.5 \%)$ than in domicile dogs $(13.3 \%) \quad(\mathrm{P}=0.007)$. The infection rate of Isospora $\mathrm{sp}$ was almost similar in both categories of dogs, domicile $(17.8 \%)$ and stray $(17.5 \%) \quad(P=0.966)$. Multiple infection and house type is shown in Table 4. In the multiple infection category mixed infections of Anchylostoma sp and Cryptosporidium sp was seen in stray dogs $(12.7 \%)$ as well as mixed infections of Anchylostoma sp, Cryptosporidium $\mathrm{sp}$ and Isospora (3.2\%). It was observed that multiple infections were higher in stray but less in domicile dogs. $(\mathrm{p}=0.051)$.

The prevalence of intestinal parasites found in this study especially in stray dogs $(68.3 \%)$, revealed a very high level of infection that requires an effective antiparasite control program. Worldwide, there are many studies on prevalence of intestinal protozoan parasites in dogs (Oliveira-Sequeira et al., 2002; Ramirez-Barrios et al., 2004; Dubna et al., 2007; Mundim et al., 2007; Papazahariadou et al., 2007; Rimhanen-Finne et al., 2007; Palmer et al., 2008; Little et al., 2009) with the estimate prevalences of dog intestinal parasites varying from 5 to $70 \%$ (Blagburn et al., 1996; Bugg et al., 1999). Prevalence is variable and depended on a number of factors including age, living conditions, diagnostic methodology employed and region studied (Mundim et al., 2007). In the present study, the intestinal protozoan parasites observed were Crysptosporidium $\mathrm{sp}$ and Isospora sp while the helminth was Anchylostoma sp. All helminth parasites detected in the faecal sample are recognized as having a public health hazard. A similar observation was documented by previous studies (Minnaar et al., 2002; Ponce Macotela et al., 2005; Labruna et al., 2006; Katagiri and Oliveira-Sequeira, 2007). Ancylostoma sp has been referred to as one on of the most frequent intestinal parasites of stray dogs. Besides A. caninum which is one of the most pathogenic species for dogs, larvae and adults of different Ancylostoma species are involved in human infections (Katagiri and Oliveira-Sequeira, 2007). Cutaneous larva migrans or creeping eruption (Velho et al., 2003) is the most common of them.

The prevalence of Crysptosporidium $\mathrm{sp}$ and Isospora sp. was (26.9\%) and (17.6\%) respectfully while that of Anchylostoma sp. was also $(26.9 \%)$. The prevalence of intestinal protozoan observed in the present study was higher than the overall prevalence of intestinal protozoan reported elsewhere; in Australia (9.4\%) (Palmer et al., 2008), Greece (4.3\%) (Papazahariadou et al., 2007), Finland (5\%) (Rimhanen-Finne et al., 2007), United States (4\%) (Little et al., 2009). The difference in prevalence may probably have resulted from difference in geographical locations and high standard of living. The present study was done in a developing country Nigeria, where the level of hygiene is considerably low.

In many African countries, including Nigeria, appropriate policies regarding pet ownership and their effects on individual and community health are nonexistent. Prevalence 
of parasite infection in dogs with importance for human health is usually high, resulting in risk of zoonotic transmission from dogs to humans. The risk is further increased by nonfavourable ecological and human behavioural factors (Dada et al., 1979; Malgor et al., 1996; Patz et al., 2002). The law guiding pet keeping in Nigeria is not usually obeyed as it is a common sight seeing animals such as cattle, goats, pigs, cats and dogs to mention few on the streets aimlessly. This is not the case in the developed world, hence less polluted environment. In addition, the present study took place in the sub-Sahara Africa where ambient temperature is high. This favours easy maturation of larvae and oocysts as it is not the case in the temperate countries where less prevalences were reported. The overall prevalence intestinal parasites of $(59.3 \%)$ is similar with the findings of Papini et al. (2005) and Szenasi et al. (2007) who discovered high prevalence of infection of $55.2 \%$ and $58.8 \%$ in dogs respectively elsewhere.

Dogs of age 1 year old were most infected $(77.8 \%)$ while dogs of age 2 years old were least infected (56.2\%) Table 1. Low immune status may have probably resulted into the difference. In this study, the difference between parasitic infection and sex of the dogs were not statistically significant. But the difference between parasitic infection of Crysptosporidium sp. and sex was however significant, females dogs were more infected $(48.9 \%)(\mathrm{P}<0.001)$. The high infection rate found in female dogs might probably have led to increase in infection of age one year old dogs. The infection may have been acquired during close contact from birth to weaning age. Epidemiological studies on the prevalence of Cryptosporidium in dogs showed that the infection rates are variable according to geographic area and range from $1.4 \%$ in Czech (Dubna et al., 2007), 1.4\% Uberlandia (Mundim et al., 2007), to $2.41 \%$ in Brazil (Huber et al., 2005). The likelihood of finding a source of oocyst could explain differences in prevalence between different areas. Other researchers suggested that prevalence may be highest in dogs from rural environments, since cryptosporidiosis is primarily associated with farm livestock (Causape et al., 1996). Grimason et al. (1993) and coworker found $1 \%$ of the faecal specimen collected in seven public parks in Scotland contained Cryptosporidium oocysts, with a prevalence in individual parks ranging from $0-2.4 \%$. In this study, no statistical differences between infection with Cryptosporidium spp. and ages of the dogs were found. This confirms the study of Causape et al. (1996). The overall prevalence of intestinal parasites in dogs by house type is shown in Table 3. The stray dogs were more infected with intestinal parasitic infection $(68.3 \%)$ than domicile dogs $(46.7 \%)$. More of Cryptosporidium sp was observed among strayed dogs $(36.5 \%)$ and least infections also Cryptosporidium sp was seen in dogs kept indoor $(13.3 \%)$. The heavy parasitaemia observed in stray dogs than in domicile support the fact the stray dogs were more exposed to these parasitic infections through contact with polluted environment than domicile dogs. Other researchers suggested that prevalence may be highest in dogs from rural environments, since cryptosporidiosis is primarily associated with farm livestock (Causape et al., 1996). Another very common parasite found in the evaluated dogs was Isospora spp. (17.6\%) which shows that these coccidia are the main intestinal protozoa found in these pets, as indicated by Vanparijs et al. (1991), Visco et al. (1997) and RamirezBarrios et al. (2004). The prevalence of $(17.6 \%)$ in this study was higher than the report of Vanparijs et al. (1991), who observed an Isospora spp. prevalence of 5.2\% in dogs in Belgium.

In conclusion, dogs have beneficial effects in their associations with humans. They contributed to physical, social and emotional well-being of their owners, particularly children (Dohoo et al., 1998; Robertson et al., 2000). However, in spite of the beneficial effects, close bond between 
dogs and humans remain a major threat to public health, with dogs harboring a bewildering number of infective stages of disease causative agents transmissible to man and other domestic animals (Robertson et al., 2000; Molyneux, 2004). Furthermore, pet keeping is usually associated with certain responsibilities like housing, disease management and responsible for pet ownership with negative consequences for public health when neglected (William et al., 2002). Since pets share the same environment with humans, they constitute an important reservoir of zoonotic diseases (Kornblatt and Schantz, 1980). Household pets have been found to play a direct role in transmitting zoonosis (Dada et al., 1979; Kornblatt and Schantz, 1980). Review of literatures revealed that at least 36 important zoonotic diseases are acquired from dogs worldwide (Tarafder and Samad, 2010). Therefore, it is important that a consistent programmed of sanitary education be included public health government actions as a first step for the control of intestinal parasites in dogs. Finally, veterinary school should emphasize the client education in training veterinarians as a means to prevent or minimize zoonotic disease transmissions. People should practice good sanitation and hygiene to minimize environmental contamination and contact with the infectious oocysts that may be shed by their pets.

Table 1: Prevalence of intestinal parasites in stray and domicile dogs stratified by age.

\begin{tabular}{lccccc}
\hline $\begin{array}{l}\text { Age } \\
(\text { years })\end{array}$ & $\begin{array}{c}\text { No examined } \\
(\boldsymbol{\%})\end{array}$ & $\begin{array}{c}\text { No infected } \\
(\boldsymbol{\%})\end{array}$ & $\begin{array}{c}\text { Anchylostoma sp } \\
(\boldsymbol{\%})\end{array}$ & $\begin{array}{c}\text { Cryptosporidium sp } \\
(\boldsymbol{\%})\end{array}$ & $\begin{array}{c}\text { Isospora } \mathbf{s p} \\
(\boldsymbol{\%})\end{array}$ \\
\hline 1 & $9(8.3)$ & $7(77.8)$ & $3(33.3)$ & $4(44.4)$ & $0(0.0)$ \\
2 & $64(59.3)$ & $36(56.2)$ & $16(25.0)$ & $18(28.1)$ & $11(17.2)$ \\
3 & $31(28.7)$ & $18(58.1)$ & $9(29.0)$ & $6(19.4)$ & $7(22.6)$ \\
4 & $4(3.7)$ & $3(75.0)$ & $1(25.0)$ & $1(25.0)$ & $1(25.0)$ \\
Total & 108 & $64(59.3)$ & $29(26.9)$ & $29(26.9)$ & $19(17.6)$ \\
\hline & & $\mathrm{X}^{2}=0.386$ & $\mathrm{X}^{2}=2.365$ & $\mathrm{X}^{2}=2.612$ \\
& & & $\mathrm{P}=0.943$ & $\mathrm{P}=0.500$ & $\mathrm{P}=0.455$ \\
\hline
\end{tabular}

Table 2: Prevalence of intestinal parasites stray and domicile dogs stratified by sex.

\begin{tabular}{lccccc}
\hline Sex & $\begin{array}{c}\text { No examined } \\
(\boldsymbol{\%})\end{array}$ & $\begin{array}{c}\text { No infected } \\
(\boldsymbol{\%})\end{array}$ & $\begin{array}{c}\text { Anchylostoma } \mathbf{s p} \\
(\boldsymbol{\%})\end{array}$ & $\begin{array}{c}\text { Cryptosporidium sp } \\
(\boldsymbol{\%})\end{array}$ & $\begin{array}{c}\text { Isospora sp } \\
(\boldsymbol{\%})\end{array}$ \\
\hline Male & $63(58.3)$ & $33(52.4)$ & $17(27.0)$ & $7(11.1)$ & $13(20.6)$ \\
Female & $45(41.7)$ & $31(68.9)$ & $12(26.7)$ & $22(48.9)$ & $6(13.3)$ \\
Total & 108 & $64(58.3)$ & $29(26.9)$ & $29(26.9)$ & $19(17.6)$ \\
P value & & 0.085 & 0.971 & 0.000 & 0.326 \\
\hline
\end{tabular}


Table 3: Prevalence of intestinal parasites in the dogs by house type.

\begin{tabular}{lccccc}
\hline House type & No examined & No infected & $\begin{array}{c}\text { Anchylostoma sp } \\
(\boldsymbol{\%})\end{array}$ & $\begin{array}{c}\text { Cryptosporidium sp } \\
(\boldsymbol{\%})\end{array}$ & $\begin{array}{c}\text { Isospora sp } \\
(\boldsymbol{\%})\end{array}$ \\
\hline Domicile & $45(41.7)$ & $21(46.7)$ & $9(20.0)$ & $6(13.3)$ & $8(17.8)$ \\
Stray & $63(58.3)$ & $43(68.3)$ & $20(31.7)$ & $23(36.5)$ & $11(17.5)$ \\
Total & 108 & $64(59.3)$ & $29(26.9)$ & $29(26.9)$ & $19(17.6)$ \\
P value & & 0.024 & 0.174 & 0.007 & 0.966 \\
\hline
\end{tabular}

Table 4: Multiple infection and house type of dogs.

\begin{tabular}{lcccc}
\hline House type & \multicolumn{3}{c}{ Multiple Infection } & \multirow{2}{*}{ P value } \\
\cline { 2 - 4 } & $\begin{array}{c}\text { Single (\%) } \\
\text { Ancy/Crypt/Isos }\end{array}$ & $\begin{array}{c}\text { Double (\%) } \\
\text { Anchy+Crypto }\end{array}$ & $\begin{array}{c}\text { Triple (\%) } \\
\text { Ancy+Crypt+Isos }\end{array}$ & \\
\hline Domicile dogs & $18(40.0)$ & $4(4.4)$ & $0(0.0)$ & 0.051 \\
Stray dog & $33(52.4)$ & $8(12.7)$ & $2(3.2)$ & \\
\hline \multicolumn{2}{l}{ Ancy= Anchylostoma } & sp, Crypt=Cryptsporidium sp, Isos= Isospora sp. &
\end{tabular}

\section{ACKNOWLEDGEMENTS}

The authors are grateful for the support of dog owners consulted both the domicile and stray in providing informations about their dogs and provision of the stool specimens.

\section{REFERENCES}

Blagburn BL, Lindsay DS, Vaughan JL, Rippey NS, Wright JC, Lynn RC, Kelch WJ, Ritchie GC, Hepler DI. 1996. Prevalence of canine parasites based on fecal flotation. Compend. Contin. Educ. Pract. Vet., 18: 483-509.

Bugg RJ, Robertson ID, Elliot AD, Thompson RC. 1999. Gastrointestinal parasites of urban dogs in Perth, Western Australia. Vet. J., 157: 295-301.

Causape AC, Quilez J, Sanchez-Acedo C, Del Cacho E. 1996. Prevalence of intestinal parasites, including Cryptosporidium parvum, in dogs in Zaragoza city, Spain. Vet. Parasitol., 67: 161-167.

Cheesbrough M. 2009. Medical Laboratory Mannual for Tropical Countries. (Part 1 $2^{\text {nd }}$ edn). Cambridge University Press: New York; 192-198

Dada BJO, Adeboye DS, Mohammed AN 1979. The epidemiology of Echinococcus infection in Kaduna State, Nigeria. Vet Rec., 104: 312-313.

Dohoo IR, McDonell WN, Rhodes CS, Elazhary YL. 1998. Veterinary research and human health. Canadian Veterinary Journal, 39: 549-556.

Dubna S, Langrova I, Napravnik J, Jankovska I, Vadlejch J. 2007. The prevalence of intestinal parasites in dogs from Prague, rural areas and shelters of the Czech Republic. Vet. Parasitol., 145: 120-128.

Edet A, Itoro U, Theophilus J, Ekpenyong A, Imaobong U. 2014. Gastrointestinal Parasites Incidence and Prevalence Rate among Dogs in Ibiono Ibom Local Government Area, Akwa Ibom State, Nigeria. Current Research in Microbiology and Biotechnology, 2(1): 289-291

Grimason AM, Smith HV, Parker JFW, Jackson MH, Smith PG. 1993. Occurrence of Giardia sp. cysts and 
Cryptosporidium sp. Oocysts in faeces from public parks in the west of Scotland. Epidemiol. Infect., 110: 641-645.

Huber F, Bomfim TCB, Gomes RS. 2005. Comparison between natural infection by Cryptosporidium sp., Giardia sp. In dogs in two living situations in the West Zone of the municipality of Rio de Janeiro. Vet. Parasitol., 130: 69-72.

Katagiri S, Oliveira- Sequeira TCG. 2007. Prevalence of dogs' intestinal parasites and risk perception of zoonotic infection by dog owners in Sao Paulo State, Brazil. Zoonoses and Public Health., 55: 406413.

Kornblatt AN, Schantz PM. 1980. Veterinary and public health considerations in canine roundwormcontrol. A survey of practicing veterinarians. Journal of American Veterinary Medical Association, 195:1212-1215.

Labruna MB, Pena HFJ, Souza SLP, Pinter A, Silva JCR, Ragozo AMA, Camargo LMA, Gennari SM. 2006. Prevalence of endoparasites in dogs from the urban area of Montenegro municipality, Rondonia, Brazil. Arq. Inst. Biol., 73: 183-193.

Little SE, Johnson EM, Lewis D, Jaklitsch RP, Payton ME. 2009. Prevalence of intestinal parasites in pet dogs in the United States. Vet. Parasitol., 166: 144152.

Malgor R, Oku Y, Gallardo R, Yarzabal I. 1996. High prevalence of Ancylostoma species infection in dogs associated with endemic focus of human cutaneous larva migrans in Tacuaremba Uruguay. Parasite, 3: 131-134.

Mundim MJS, Rosa LAG, Hortêncio SM, Faria ESM, Rodr RM. 2007. Prevalence of Giardia duodenalis and Cryptosporidium spp. In dogs from different living conditions in Uberlândia, Brazil. Vet. Parasitol., 144: 356-359.
Molyneux DH. 2004. Neglected diseases but unrecognized successes-challenges and opportunities for infectious disease control. Lancet, 364: 380 - 283.

Okoye IC, Obiezue NR, Okorie CE, Ofoezie IE. 2011. Epidemiology of intestinal helminth parasites in stray dogs from markets in south-eastern Nigeria. Journal of Helminthology, 85: 415-420.

Oliveira-Sequeira TCG, Amarante AF, Ferrari TB, Nunes LC. 2002. Prevalence of intestinal parasites in dogs from Sao Paulo State, Brazil. Vet. Parasitol., 103: 19-27.

Patz JA, Gractzyk TK, Gella N, Vittor AY. 2002. Effects of environmental changes on emerging parasitic diseases. Int $J$ Parasitol, 30: 1395-1405.

Papini R, Gorini, G, Spaziani A, Cardini G. 2005. Survey on giardiosis in shelter dog populations.Vet. Parasitol., 128: 333-339.

Palmer CS, Thompson RCA, Traub RJ, Rees R, Robertson ID. 2008. National study of the gastrointestinal parasites of dogs and cats in Australia. Vet. Parasitol., 151: 181-190.

Papazahariadou M, Founta A, Papadopoulos E, Chliounakis S, Antoniadou-Sotiriadou K. 2007. Gastrointestinal parasites of shepherd and hunting dogs in the Serres Prefecture, Northern Greece. Vet. Parasitol., 148: 170-173.

Ramirez-Barrios RA, Barboza-Mena G, Muoz J, Angulo-Cubillan F, Hernandez E. 2004. Prevalence of intestinal parasites in dogs under veterinary care in Maracaibo, Venezuela. Vet. Parasitol., 121: 11-20.

Rimhanen-Finne RHL, Enemark J, Kolehmainen PT, Hanninen ML. 2007. Evaluation of immunofluorescence microscopy and enzyme-linked immunosorbent assay in detection of Cryptosporidium and Giardia infections 
in asymptomatic dogs. Vet. Parasitol., 145: 345-348.

Robertson ID, Irwin PJ, Lymbery AJ, Thompson RCA. 2000. The role of companion animals in the emergence of parasitic disease. International Journal of Parasitology, 30: 1369-1377.

Szenasi Z, Marton S, Kucsera I, Tanczos B, Horvath K. 2007. Preliminary investigation of the prevalence and genotype distribution of Giardia intestinalis in dogs in Hungary. Parasitol. Res., 101: 145-152.

Tarafder M, Samad MA. 2010. Prevalence of clinical diseases of pet dogs and risk perception of zoonotic infection by dog owners in Bangladesh. Bangl. J. Vet. Med., 8(2): 163 - 174.
Vanparijs O, Hermans L, Van Der Flaes L. 1991. Helminth and protozoan parasites in dogs and cats in Belgium. Vet. Parasitol., 38: 67-73.

Vellho PENF, Faria AV, Cintra Ml, Souza EM, Moraes AM. 2003. Larva migrans: a case report and review. Rev. Inst. Med. Trop. Sao Paulo., 45: 167-17.

William A, Chaudharti SUR, Atsanda NN. 2002. Prevalence of some diseases of dogs and cats at the State Government Veterinary Clinic in Maiduguri-Nigeria. International Journal of Agriculture and Biology, 4: 568-569.

World Health Organization. 1992. World Society for Protection of Animals. Guidelines for the dog population management. World Health Organization: Genebra; 212. 